\title{
Rosette formation by peripheral blood lymphocytes in rheumatoid arthritis
}

\author{
H. I. KEITH AND H. L. F. CURREY \\ Bone and Joint Research Unit, London Hospital Medical College
}

Rosette formation, a phenomenon in which a leucocyte becomes surrounded by a cluster of erythrocytes (Fig. 1) may occur in a variety of circumstances. For example, when lymphocytes from an animal which has been immunized against erythrocytes of another species are mixed with a suspension of the foreign red cells, a certain proportion of the lymphocytes will form rosettes (Biozzi, Stiffel, Mouton, Bouthillier, and Decreusefond, 1968). This immunocytoadherence is one means of following an immune response at the cellular level. Bach (1970) and Bach and Dormont (1971) pointed out that a small fraction (1 per cent. or less) of the lymphocytes of some non-immune laboratory animals, and of man, form rosettes when mixed with sheep erythrocytes. These spontaneous rosette-forming cells (RFC) he

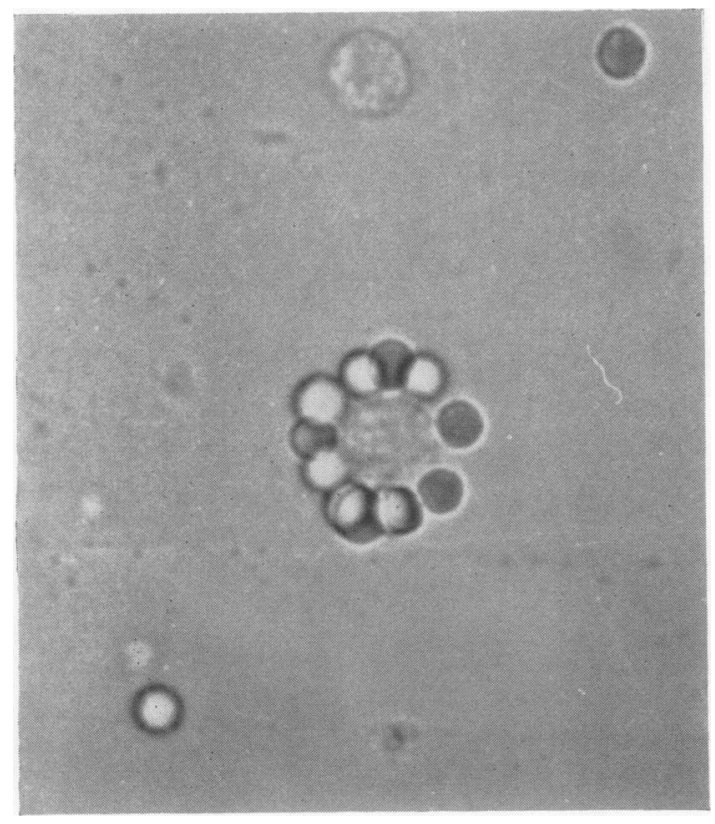

FIG. 1 Rosette showing sheep erythrocytes adherent to a lymphocyte interpreted (Bach, 1971) in terms of Burnet's clonal selection theory (Burnet, 1959) as being long-lived recirculating small lymphocytes able to recognize some antigen on the red cell surface, that is 'antigen recognition cells'. Spontaneous rosette formation assumed a practical importance when Bach, Dardenne, and Fournier (1969a) showed that the phenomenon was readily inhibited by pre-incubation of the lymphocytes with high dilutions of antilymphocyte serum (ALS) or with serum from patients taking azathioprine. Indeed, this system provides a means of determining the potency of ALS which it is claimed correlates well with the survival of skin grafts in primates (Bach, Dormont, Dardenne, and Balner, 1969b).

This observation was the starting point of our investigation. It seemed possible that azathioprine therapy might modify the numbers of spontaneous rosette-forming cells in the peripheral blood of rheumatoid subjects receiving this antimetabolite. If so, serial determinations might provide a means of monitoring this form of therapy. In the event we were disappointed in this, but our study led to other and unexpected observations about spontaneous rosetteforming cells.

\section{Materials and methods}

\section{PATIENTS}

Samples of blood were obtained from 207 patients with rheumatoid arthritis, of whom 49 were being treated with gold in conventional dosage, 43 were receiving azathioprine $(2.5 \mathrm{mg} . / \mathrm{kg} . / \mathrm{day})$, and thirty cyclophosphamide $(1.5 \mathrm{mg} . / \mathrm{kg}$./day). 68 of the patients had osteoarthrosis and 23 were normal controls. Fifteen patients suffering from chronic lymphatic leukaemia were also tested. Samples of thymus, spleen, and lymph nodes were obtained fresh from operating theatres.

SEPARATION OF LYMPHOCYTES

Eight $\mathrm{ml}$. of venous blood were mixed with heparin (sodium heparin tube, Stayne Laboratories Ltd.) and processed within 12 hrs. A crude preliminary separation 
was achieved by mixing four parts of blood with one of Plasmagel (Laboratoire Roger Bellon, Neuilly) and allowing the erythrocytes to sediment at $37^{\circ} \mathrm{C}$. for $30 \mathrm{~min}$. The leucocyte rich supernatant was then layered on to a Ficoll/Triosil mixture (Harris and Ukaejiofo, 1969) and centrifuged at $3500 \mathrm{G}$. for 15 minutes. The lymphocytes at the interface were aspirated ( $c a .95$ per cent. pure) and washed twice in phosphate buffered saline (PBS) $(\mathrm{pH} 7 \cdot 2)$ containing heparin $5 \mathrm{u} . / \mathrm{ml}$. and the concentration adjusted to $c a .5 \times 10^{6} \mathrm{cells} / \mathrm{ml}$. in Hanks's balanced salt solution (pH 7.2) containing heparin $5 \mathrm{u} . / \mathrm{ml}$. and 10 per cent. foetal calf serum (FCS) (Burroughs Wellcome \& Co.) previously absorbed with both sheep and human erythrocytes. Non-wettable surfaces were used throughout all stages involving lymphocytes.

\section{ERYTHROCYTE SUSPENSION}

Sheep erythrocytes (SRBC) in Alsever's solution (Burroughs Wellcome \& $\mathrm{Co}$.) were washed twice in PBS, then mixed as a 0.5 per cent. suspension in Hanks's solution (pH 7.2) containing 10 per cent. absorbed FCS.

\section{ROSETTE FORMATION (Fig. 2)}

$0.5 \mathrm{ml}$. of the lymphocyte suspension was mixed with an equal volume of the SRBC suspension and centrifuged at 180G. for $5 \mathrm{~min}$. at room temperature. The mixture then stood for $30 \mathrm{~min}$. at $4^{\circ} \mathrm{C}$. before being gently resuspended on a Matburn mixer at 27 r.p.m. for $5 \mathrm{~min}$. and immediately counted in a haemocytometer chamber.

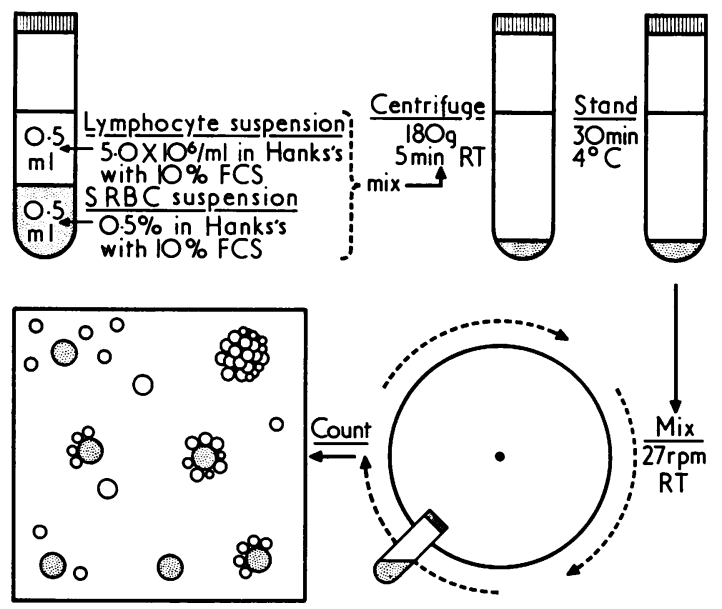

FIG. 2 Technique of rosette formation (see Methods)

\section{ENUMERATION}

A rosette was defined as a lymphocyte to which a minimum of five SRBC were adherent. Most of the RFC were surrounded by many SRBC forming a morula. Rosettes were counted in at least four large squares and lymphocytes in one large square of the improved Neubauer chamber. The result was expressed as rosette-forming cells per 100 lymphocytes.

\section{STANDARDIZATION OF TECHNIQUE}

The use of heparinized rather than defibrinated blood increased the yield of lymphocytes. Similarly, inclusion of the plasmagel stage did not alter the percentage of RFC, but it improved the yield and purity of lymphocytes from severely ill patients. Unlike Bach and Dormont (1971) we did not find that red cell contamination seriously affected the results.

Centrifugation with Ficoll/Triosil was found to be the best method of purifying lymphocytes. Nylon-wool column filtration followed by haemolysis of the red cells (Bach and others, 1969b) gave a poorer yield of lymphocytes and a lower percentage of RFC.

The stage in which the centrifuged cell pellet stood at $4^{\circ} \mathrm{C}$. for $30 \mathrm{~min}$. (Lay, Mendes, Bianco, and Nussenzweig, 1971) was critical in achieving consistent results. Its omission produced lower and variable figures; whereas similar values were obtained after standing for $30 \mathrm{~min}$. or $60 \mathrm{~min}$. at $4^{\circ} \mathrm{C}$. In a few cases FCS was omitted and did not appreciably affect the result.

\section{Results}

Our initial attempts to determine the numbers of RFC produced variable results with poor reproducibility. It was only after optimal conditions for a number of variables in the technique had been established that satisfactorily reproducible results were obtained. The technique described above represents these conditions.

20 to 40 per cent. (mean 29 per cent.) of lymphocytes from the peripheral blood of normal human subjects formed rosettes. Similar figures were obtained for patients with osteoarthrosis (mean 30 per cent.) and rheumatoid arthritis (mean 30 per cent.) (Fig. 3).

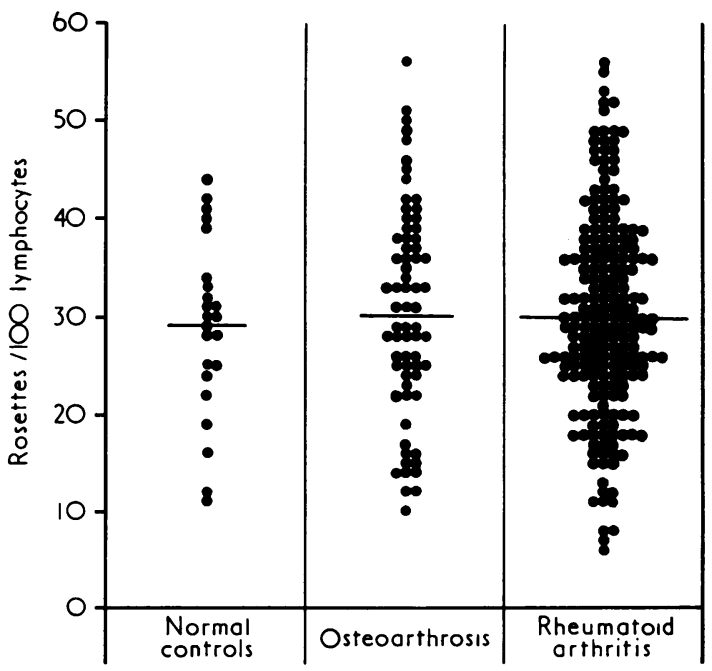

FIG. 3. Percentages of peripheral blood lymphocytes forming rosettes: comparison of normal controls and patients with osteoarthrosis and rheumatoid arthritis

Samples from rheumatoid subjects taking part in a double-blind clinical trial comparing azathioprine 
( $2.5 \mathrm{mg} . / \mathrm{kg} . / \mathrm{day})$, cyclophosphamide $(1.5 \mathrm{mg} . / \mathrm{kg} . /$ day), and sodium aurothiomalate showed similar results. No differences were apparent between the treatment groups or rheumatoid patients receiving none of these drugs (Fig. 4). When absolute numbers (as opposed to percentages) were considered, the cyclophosphamide figures particularly were scattered slightly lower, but this merely reflected the somewhat irregular reduction in total lymphocyte counts seen amongst this treatment group (i.e. cyclophosphamideinduced lymphopenia appeared to affect rosetting and non-rosetting lymphocytes equally). Steroid therapy also did not modify the proportion of cells forming rosettes. Age (within the range tested) and sex had no effect on the percentage of RFC.

Despite these negative results it appeared likely that the phenomenon of rosetting was a marker for a subgroup of lymphocytes which was functionally significant. We therefore applied the test to blood from patients suffering from diseases affecting the lymphatic cell system. One disease, chronic lymphatic leukaemia, gave highly informative results.

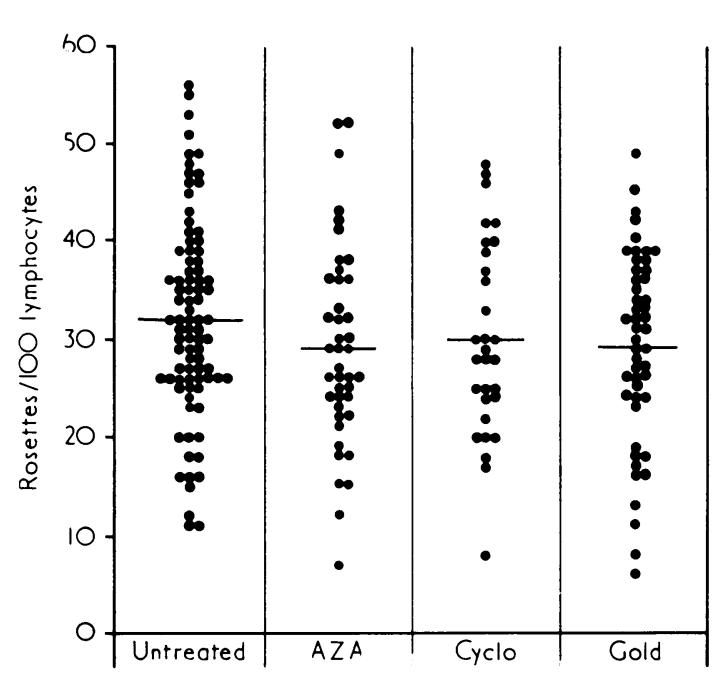

FIG. 4 Percentages of rosette-forming cells amongst the peripheral blood lymphocytes of patients with rheumatoid arthritis: comparison of groups treated with azathioprine $(A Z A)$, cyclophosphamide $(C y c l o)$, gold, or none of these drugs

Testing patients with chronic lymphatic leukaemia showed that generally these subjects had very low percentages of RFC in the peripheral blood (1 to 11 per cent.). However, when absolute numbers of RFC were considered, it became clear that these did not depart greatly from normal, despite gross variations in the total lymphocyte counts. This is illustrated in Figs 5 and 6, from which it is clear that these patients suffered from a proliferation of non-rosetting lymphocytes.

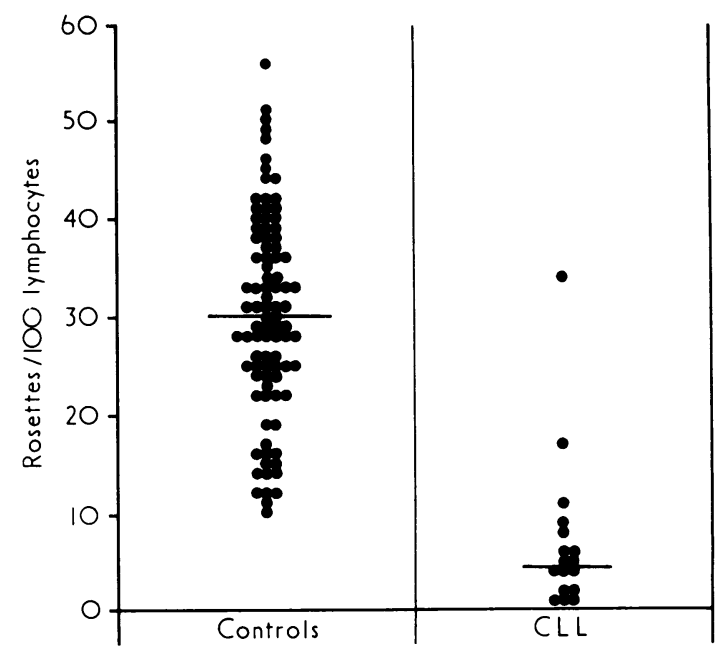

FIG. 5 Percentages of peripheral blood lymphocytes forming rosettes in controls and in patients with chronic lymphatic leukaemia (CLL)

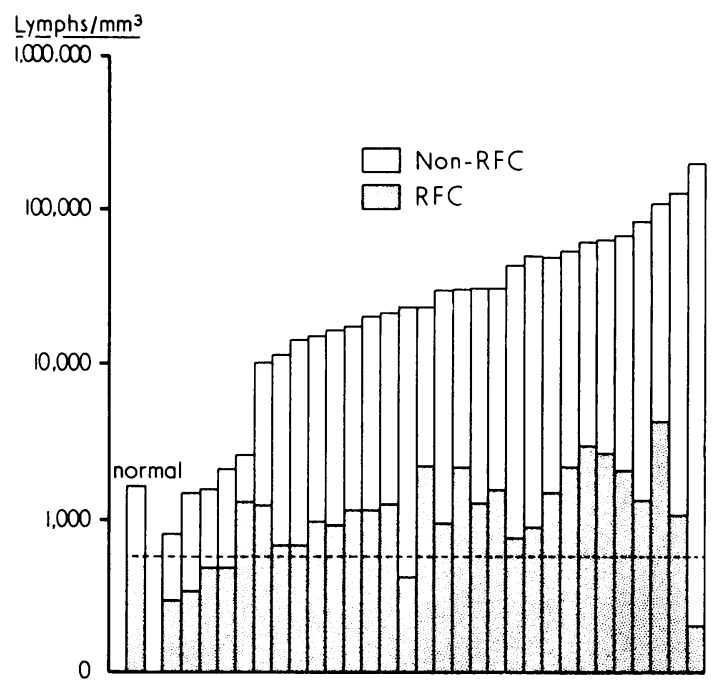

FIG. 6 Absolute numbers (per $\mathrm{mm}^{3}$.) of rosette-forming cells (RFC) and non-rosetting cells in the peripheral blood of individual patients with chronic lymphatic leukaemia. The first column indicates the average distribution amongst 91 control patients. The scale is logarithmic

Information about the percentages of rosetteforming cells amongst the lymphocytes suspended from solid lymphatic tissues was collected by applying the test to material obtained from the operating theatres. Lymphocytes from thymus tissue yielded 42 to 96 per cent. (mean 69 per cent.) rosette-forming cells. 18 to 33 per cent. (mean 26 per cent.) rosetting cells were obtained from the spleen, and lymph nodes produced intermediate results (33 to 55 per cent., mean 42 per cent.) (Fig. 7, opposite). 


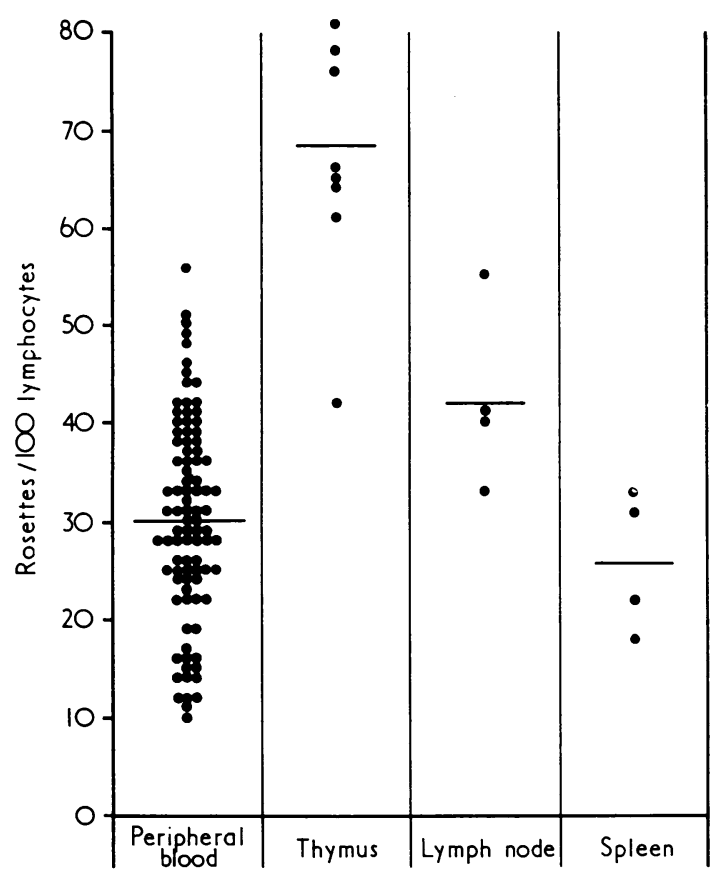

FIG. 7 Percentages of rosette-forming cells amongst lymphocytes obtained from specimens of thymus, lymph nodes, and spleen

Mononuclear cells (purified in the manner described above) from five samples of synovial fluid from affected joints in rheumatoid subjects yielded results (20 to 40 per cent.) comparable with those from peripheral blood.

\section{Discussion}

Our finding, that 30 per cent. or more of human peripheral blood lymphocytes will form rosettes with sheep erythrocytes, has been reported by others, notably Brain, Gordon, and Willetts (1970), Coombs, Gurner, Wilson, Holm, and Lindgren (1970), and Lay and others (1971). Recently Jondal, Holm, and Wigzell (1972), using a modified procedure, obtained figures as high as 60 per cent. Such high percentages clearly exclude these rosette-forming cells from being 'antigen recognition cells' in the sense proposed by Bach (1971). It is significant that the phenomenon is not inhibited by pre-treatment of the lymphocytes with anti-Ig or anti-light-chain antiserum (Papamichail, Holborow, Keith, and Currey, 1972) and does not correlate with the presence or absence of heterophil antibody to sheep erythrocytes (Brain and others, 1970).

The characteristics of the proliferating cells in chronic lymphatic leukaemia have been studied by a number of different techniques. Papamichail, Brown, and Holborow (1971) used membrane fluorescent staining to show that these cells have a high density of immunoglobulins on their surface. We subsequently collaborated with these workers and applied simultaneously the techniques of membrane staining and rosette formation to samples of blood from patients with chronic lymphatic leukaemia. This showed (Papamichail and others, 1972) that the tests identified two separate populations of lymphocytes: proliferating cells bearing surface immunoglobulin and non-proliferating cells which formed rosettes. The presence of immunoglobulin on the surface of the former suggested that these were 'B-cells' and thus that the latter might be 'T-cells'. Our findings of a relatively high proportion of RFC in the thymus appeared to support the identity of spontaneous RFC as 'T-cells'.

Work from a number of different laboratories supports the ' $T$-cell' identity of the RFC identified in the manner described here. In particular, Silveira, Mendes, and Tolnai (1972) have applied the test to human solid lymphoid tissues and shown that the distribution of RFC corresponds with the distribution of 'thymus-derived' areas in these tissues. By contrast, the modified rosette test described by Bianco, Patrick, and Nussenzweig (1970), in which the sheep erythrocytes are coated with antibody and complement, appears to provide a comparable marker for 'B-cells'.

By use of these various techniques it is now feasible to study the distribution of 'T-cells' and 'B-cells' amongst the peripheral blood lymphocytes in different disease states. Our results in patients with chronic lymphatic leukaemia were highly informative. By contrast we were unable to detect any alteration in this cell ratio amongst patients with rheumatoid arthritis (despite the finding by Papamichail and others (1971) that such patients show an increased proportion of peripheral blood lymphocytes with immunoglobulin on their surface). Amongst rheumatoid subjects, we failed to show any change attributable to treatment with the 'immunosuppressive' agents azathioprine or cyclophosphamide (or with gold). Disappointingly, therefore, this does not provide a means of monitoring 'immunosuppressive' therapy in rheumatic diseases. Rheumatoid synovial fluid lymphocytes appear to have the same distribution of the two cell types as peripheral blood.

\section{Conclusion}

Under carefully controlled conditions, 30 per cent. or more of human peripheral blood lymphocytes can be shown to form rosettes with sheep erythrocytes. The proportion of such cells in the peripheral blood of rheumatoid subjects does not differ from normal controls and is not altered significantly by therapy with gold, azathioprine, cyclophosphamide, or 
adrenal corticosteroids. A similar proportion of small mononuclear cells in the synovial fluid of rheumatoid joints exhibit rosette formation. The phenomenon of spontaneous rosette formation defines a subpopulation of lymphocytes corresponding to 'T-cells' identified by other techniques. Rosette formation is a simple test and should be a useful tool in further research on lymphocytes.

\section{Discussion}

DR. P. J. L. HOLT (London) I do not fully agree that the cell in chronic lymphocytic leukaemia is a B cell, because its surface is completely different from that of most other lymphocytes. It is thicker and has a different chemical composition. You can in appropriate conditions make it perform very like a $\mathrm{T}$ cell.

DR. KEITH It is very difficult to decide on what one should call a B cell or a $\mathrm{T}$ cell and one should not be too dogmatic at the present time.

DR. R. N. MAINI (London) In the studies you performed with Dr. Holborow your totals could not have added up to 100 per cent.- there must have been a considerable number of unlabelled cells.

DR. KEITH Exactly. The lymphocyte population is very variable and there must be subpopulations. By Dr. Holborow's technique some 30 per cent. of peripheral lymphocytes stained by immunoglobulin are B cells. My rosette test also forms rosettes in about 30 per cent. that means there is about another $\mathbf{4 0}$ per cent. to account for.

DR. R. N. MAINI (London) Have you used any double techniques to see if any of your apparent $T$ cells show any immunoglobulin on their surface?

DR. KEITH Yes, I can demonstrate lymphocytes coated with immunoglobulin that never form rosettes. When rosettes are formed there is never any immunoglobulin on the lymphocyte surface. We have done this first of all by mixing the lymphocytes with anti-immunoglobulin conjugate antiserum and then washing off all the excess antiserum and then forming the rosettes. Also, there is no blocking by anti-immunoglobulin to stop rosette formation. There are two definite separate populations.

DR. CURREY Perhaps I should draw attention to the recent paper from Sweden (Stjernswärd, Jondal, Vánky, Wigzell, and Sealy, 1972), which reports a similar study in patients irradiated for carcinoma of the breast. They obtained different results from us, showing about 60 per cent. $\mathrm{T}$ cells. They are the only workers to obtain these higher figures; they left the specimens overnight at $4^{\circ} \mathrm{C}$. in a centrifuged state and used a different method of resuspending them. I know Dr. Keith repeated some tests after 24 hours-what were the results?

DR. KEITH I got about 40 per cent. $T$ cells by the next morning on two specimens. I did not manage 60 per cent.

\section{References}

BACH, J. F. (1970) Lancet, 1, 565 (Antigen-binding lymphocytes)

- (1971) Ann. rheum. Dis., 30, 565 (Antigen recognition by T-cells and its suppression. Significance and origin of rosette-forming cells)

_, DARDENNE, M., AND FouRnier, C. (1969a) Nature (Lond.), 222, 998 (In vitro evaluation of immunosuppressive drugs)

AND DoRmont, J. (1971) Transplantation, 11, 96 (Further developments of the rosette inhibition test for the testing of antihuman lymphocyte serum)

- - - DARDENNE, M., AND BALNER, H. (1969b) Ibid., 8, 265 (In vitro rosette inhibition by antihuman antilymphocyte serum. Correlation with skin graft prolongation in subhuman primates)

Bianco, C., Patrick, R. And Nussenzweig, V. (1970) J. exp. Med., 132, 702 (A population of lymphocytes bearing a membrane receptor for antigen-antibody-complement complexes)

Biozzi, G., Stiffel, C., Mouton, D., Bouthillier, Y., AND DeCreusefond, C. (1968) Immunology, 14, 7 (A kinetic study of antibody producing cells in the spleen of mice immunized intravenously with sheep erythrocytes)

Brain, P., GoRdon, J., AND Willetts, W. A. (1970) Clin. exp. Immunol. 6, 681 (Rosette formation by peripheral lymphocytes)

Burnet, M. (1959) 'The Clonal Selection Theory of Acquired Immunity'. University Press, Cambridge

COOMBs, R. R. A., Gurner, B. W., Wilson, A. B., Holm, G., AND LindGren, B. (1970) Int. Arch. Allerg., 39, 658 (Rosette-formation between human lymphocytes and sheep red cells not involving immunoglobulin receptors)

HARRIS, R., AND UKAEJIOFO, E. O. (1969) Lancet, 2, 327 (Rapid preparation of lymphocytes for tissue-typing)

JoNDAL, M., Holm, G., AND Wigzell, H. (1972) J. exp. Med., 136, 207 (Surface markers on human T and B lymphocytes. I. A large population of lymphocytes forming nonimmune rosettes with sheep red blood cells)

Lay, W. H., Mendes, N. F., Bianco, C., AND NussenzWeig, V. (1971) Nature (Lond.), 230, 531 (Binding of sheep red blood cells to a large population of human lymphocytes)

Papamichail, M., Brown, J. C., AND Holborow, E. J. (1971) Lancet, 2, 850 (Immunoglobulins on the surface of human lymphocytes) 
—, Holborow, E. J., KeITH, H. I., AND CuRreY., H. L. F. (1972) Ibid., 2, 64 (Subpopulations of human peripheral blood lymphocytes distinguished by combined rosette formation and membrane immunofluorescence)

Silveira, N. P. A., Mendes, N. F., AND TolnaI, M. E. A. (1972) J. Immunol., 108, 1456 (Tissue localization of two populations of human lymphocytes distinguished by membrane receptors)

StJernSWÄrd, J., Jondal, M., VÁNKY, F., Wigzell, H., AND SEAly, R. (1972) Lancet, 1. 1352 (Lymphopenia and change in distribution of human $\mathrm{B}$ and $\mathrm{T}$ lymphocytes in peripheral blood induced by irradiation for mammary carcinoma) 